\title{
Algorithmic Cities: A Dystopic or Utopic Future?
}

\author{
Miguel de Castro Neto \& Tiago de Melo Cartaxo \\ NOVA Information Management School (NOVA IMS) Universidade NOVA de Lisboa, Lisbon, \\ Portugal \\ e-mail: mneto@novaims.unl.pt
}

This is the Author Peer Reviewed version of the following chapter published by Springer:

de Castro Neto, M., \& de Melo Cartaxo, T. (2021). Algorithmic Cities: A Dystopic or Utopic Future? In M. I. A. Ferreira (Ed.), How Smart Is Your City?: Technological Innovation, Ethics and Inclusiveness (Vol. 98, pp. 59-73). (Intelligent Systems, Control and Automation: Science and Engineering; Vol. 98). Springer Science and Business Media B.V.. https: / / doi.org/10.1007/9783-030-56926-6_6

This work is licensed under a Creative Commons Attribution-NonCommercial 4.0 International License. 


\title{
Chapter [...] Algorithmic Cities: A Dystopic or Utopic Future?
}

\author{
Miguel de Castro Neto and Tiago de Melo Cartaxo ${ }^{1}$
}

\begin{abstract}
Cities of today face a digital transformation process, leading to a new reality where urban space is taking advantage of information and communication technologies and data science to answer present and future challenges, namely to become more efficient in services and infrastructures management in order to deliver increased quality of life to the people who live, work or visit the city, and addressing at the same time the problems of climate change. This new reality is leveraged by big data produced by the cities internet of everything (as interconnected systems, sensors and people), information management and data science capabilities, which allow us to measure and describe what happens, predict what can happen, and prescribe what could be the course of actions bringing policy making to a fact-based environment, which had never been possible before. In this work we will address the opportunities and challenges of this paradigm shift that is leading to the city as a platform reality that support what we can call the algorithmic city where it is up to us to decide if this will be a dystopic or utopic future for the citizen.
\end{abstract}

Keywords: algorithmic cities; urban intelligence; city as a platform; digital transformation

\section{Introduction}

Today, $55 \%$ of the world's population lives in urban areas and. This number is expected to increase to $68 \%$ by 2050 , at a number of more 2.5 (United Nations, 2018). Cities occupy only $2 \%$ of the earth's surface (land), urban inhabitants generate $80 \%$ of the global GDP, consume $75 \%$ of global natural resources, produce $50 \%$ of global waste and emit $60-80 \%$ of greenhouse gases (UNEP, 2017). At the same time, with the development of a large number of innovative technologies, cities are facing a relevant digital transformation process (Tyagi et al, 2019:309).

This means that urban dwellers, workers, and visitors are living a new reality under a strong influence of information and communication technologies (ICTs) and data science (Navarro et al, 2017:272-280; Komninos et al, 2019).

Politicians and professionals intend cities to answer day-to-day challenges, such as more efficiency in services and infrastructures management, increased quality of life, and

M.C. Neto $(\bowtie) \cdot$ T.M. Cartaxo

NOVA Information Management School, Universidade NOVA de Lisboa

Lisbon, Portugal

e-mail: mneto@novaims.unl.pt 
addressing the problems of climate change. Therefore, cities are par excellence places where big data thrives, given that it is produced by the internet of everything (as interconnected systems, sensors and people). Additionally, information management and data science capabilities allow city managers (and also corporations) to measure and describe the realities that happen in the territory of the city. With these solutions is possible to predict what happens (very often in real time) and then take rapid decisions to prescribe what could be the actions and the following course of actions. Policy making can, consequently, more easily adapt to fact-based urban environments.

Given that this new way of governing cities has never been possible until our days, this work intends to address the opportunities and challenges of this paradigm shift. The urban areas of the future will be understood as platform realities. This idea of the city as a platform will support the new reality of an algorithmic city, where it is up to those who have the responsibility of governing it (or giving that power the citizens) to decide if the future (and even the present) of cities will be dystopic or utopic for the daily life of the citizens.

\section{An Algorithmic Urban Future}

This new reality of a "Smart City", an "Analytic City", or even an "Algorithmic City" is naturally potentiated by big data. It is produced by the internet of everything (as interconnected systems, sensors and people), information management, and data science capabilities existent in the territory of the city (Foth et al, 2020).

Although it is possible to find many definitions for this type of urban reality, which is widely acknowledged and recognized as the city of the future (but even of present days), from the current literature, they all seem to share the concept of an urban space which can take advantage of ICTs and data science to perceive and answer today's urban challenges, measuring the territory and communities and, at the same time, prescribing solutions and more general or concrete actions. Smart city solutions are becoming more efficient in services and infrastructures management and delivering increased quality of life to the people who live, work or visit the city, not forgetting the support to tackle climate change. In order to develop urban intelligence that ensures resource usage efficiency, more sustainable and inclusive cities, and concurrently, promoting economic development by boosting entrepreneurship and technological start-ups in the creation of innovative products and services for new markets, an inescapable challenge must be overcome. This challenge is city data, the true fuel of urban intelligence that should be collected or linked for release in the form of "Open Data" - data that can be used, modified, and shared by anyone for any purpose (Open Knowledge Foundation, 2018).

This opens a space to a reality where with increasing frequency, governments are using computer algorithms to conduct public affairs, at international, national, and local levels (Brauneis \& Goodman, 2018:103).

It encompasses "almost any form of technology-based innovation in the planning, development, and operation of cities" (Harrison and Donnelly, 2011; Townsend, 2013). Within the European Union (EU) the term "smart city" almost has an official status, with the European Parliament having issued a study ranking cities based on their performance in governance, human flourishing, livability, mobility, economy, and environment, assuming that: "the idea of Smart Cities is rooted in the creation and connection of human capital, social capital and information and Communication technology (ICT) 
infrastructure in order to generate greater and more sustainable economic development and a better quality of life" (European Parliament, 2014).

According to the referred study, the European Parliament adopted the following working definition for "smart city": "a city seeking to address public issues via ICT-based solutions on the basis of a multistakeholder, municipally based partnership" (European Parliament, 2014; Neto et al., 2017).

Nonetheless, other suggestions have been presented, such as the idea that a city is smart when the use of information and communications technology (ICT) makes:

"the critical infrastructure components and services of a city - which include city administration, education, healthcare, public safety, real estate, transportation, and utilities - more intelligent, interconnected, and efficient" (Washburn and Sindhu, 2010), as well as the approach "that cities are systems of systems, and that there are emerging opportunities to introduce digital nervous systems, intelligent responsiveness, and optimization at every level of system integration" (MIT, 2013).

Other interesting definition is based on the idea that a city may be called "smart" when investments in human and social capital and traditional (transport) and modern (ICT) communication infrastructure are used to "fuel sustainable economic growth and a high quality of life, with a wise management of natural resources, through participatory governance" (Schaffers et al., 2011; Caragliu et al., 2009).

As a matter of fact, according to the possible definitions presented above, the inclusion of urban fairness or inclusiveness (Oomen et al., 2016), public participation and sustainability is absolutely accepted to be included in this term, if the so-called intelligence that is present in the city (from ICT to open data) is used for improving those indicators, through innovative, open and analytical solutions, which are available and accessible for all (Meijer and Bolívar, 2016).

According to the OECD - Organisation for Economic Co-operation and Development (2015), data produced in cities can be divided into three categories:

- Flows - Cities are structured with different types of pervasive infrastructures, e.g., ICTs, transport, water, energy, waste networks, that facilitate movement and flows of resources, products, people and information throughout. Sensors embedded in urban infrastructures increasingly allow the digitisation and datafication of these flows.

- States - Urban inside spaces and outside environments are subject to constant changes, natural and manmade. The particular states of urban spaces and environments - the population density, air temperature and quality, light and sound levels, etc. - are increasingly monitored by sensors, including cameras, through synoptic instruments such as satellites or continual observations from urban vantage points.

- Activities - Connected machines and devices used for both personal and professional activities in cities allow measurement of transactions, consumption and communication patterns. These patterns specifically include: people's activities, communication and interactions; interaction between people and their environment; and interactions among components of their environments such as communicating and autonomous machines and devices.

Also in the context of urban intelligence, and its algorithmic capabilities, the spatial dimension is also referred by OECD since it plays an increasing and fundamental role since this data - created through the sensing, measuring and recording of flows, states 
and activities in cities - generates extraordinary added value potential by being locationspecific through:

- Stationary sensors embedded in urban infrastructures and environments, producing data describing flows and states in cities;

- Geo-locational and geo-referenced data generated in cities, often from mobile devices and sensors, describing the main activities (actions, interactions, transactions) of connected people, machines and devices and;

- Other data generated not necessarily displaying geographic properties, e.g., data on financial transactions or energy consumption (OECD, 2015).

\section{City as a Platform}

The process of digital transformation within urban environments has led to the vision of the "city as a platform" (Neto, 2018) where data becomes new raw material, and where true building blocks of urban intelligence can be identified.

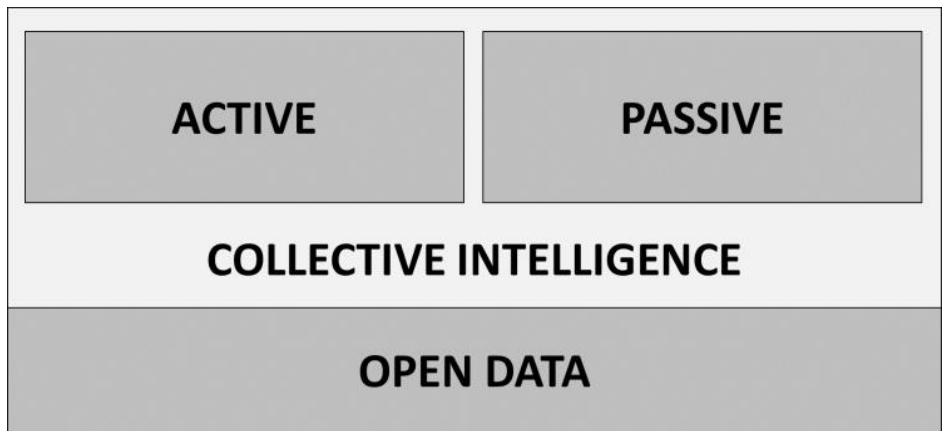

Figure 1. Urban Intelligence Building Blocks.

These building blocks of urban intelligence, as shown schematically in the figure above and detailed below, can be divided into open data (public and private) and collective intelligence. On the one hand, we have open data originating in organizational activity and collected from sensors that support these businesses or in transactions they carry out. On the other, we have data sourced from collective intelligence, compiled from citizens actions either actively or passively, which continues to gain increased relevance.

An interesting aspect of the emerging class of smart cities regards their evolution into data-opening initiatives. While the collection of mass data from operational systems, equipment, and through sensors linked to a variety of physical infrastructures has always been a feature of the first generation of smart cities, the publication of such data as open data, or its integration with open data published by urban authorities in different aspects of management and life in the city, is a relatively recent phenomenon (Ojo et al (2015:2326-2335).

The ability to create, collect and process scattered data and make it openly available is the first and also the most ambitious and disruptive urban intelligence building block. In this respect, municipalities have a key role and opportunity to unleash processes of open innovation, co-creation and collective intelligence. Citizens, companies, management and academia, as well as the third sector, will create new high value-added products and services, many of them still unimaginable, capable of generating new markets. It is up to 
the municipalities to take the first step and launch open data initiatives (supported, at first, by the internal data sources and their projects based on IoT).

Although a definition of open data exists, "data that can be used, modified and shared by anyone for any purpose" (Open Knowledge Foundation, 2018), the Full Open setting (Open Knowledge International, 2017) gives precise details about what this means. To summarize the most important characteristics:

- Availability and Access - The data must be available as a whole and have no more than a reasonable cost of reproduction, preferably downloaded over the internet. The data must also be available in a convenient and modifiable form;

- Reuse and Redistribution - Data must be provided in ways that enable reuse and redistribution, including combinations with other data sets;

- Universal Participation - Everyone should be able to use, reuse and distribute; there should be no discrimination in the fields of action or against individuals or groups. For example, "non-commercial" restrictions that would prevent "commercial" use, or restrictions of use for certain purposes, e.g., education only, are not permitted.

National and local governments, largely in North American and Europe, have been experimenting sharing their data, what has generated the spread of a vast number of citizen-based applications, the forging of new partnerships between civic organizations, and also an increased involvement in civics by the technology community.

In effect, open data has been allowing national and local governments to generate city infrastructure outside formal governmental structures, creating new possibilities for innovation and increasing information sharing, which fosters the generation of new partnerships, more innovation, more start-ups, and civic action (Williams, 2015).

At the same time, open data, public participation and engagement represent instruments of enhancing transparency and accountability, which, while following the recommendations of the Aarhus Convention, also close the relation between public officials or representatives and citizens, giving these latter more opportunities of asserting their rights and claiming for a better provision of governmental services.

The need for clarity about what it means to be "open" closely relates to interoperability. Interoperability critically achieves the key benefits of data openness: drastic increase in the ability to combine and bring together different datasets and the generation of new or better products and services (Khatoun \& Zeadally, 2016:46-57).

Open data appears increasingly as a defining element of smart cities, and, therefore, can be conceptually considered as a smart cities' initiative. Thus, it is important to understand how open data initiatives impact the context of smart cities, as well as how smart city programs affect the associated open data initiatives.

By opening data on the environment, transport, education, health and so forth, municipalities can objectively support companies, start-ups, application developers, civil society organizations, among others, to find new and improved ways of dealing with urban problems.

Open data, governmental as well as private company, is undoubtedly an extraordinary and yet largely unexplored resource. While many organizations and individuals collect large amounts of data, the government has a particularly significant role. This is not only because of the quantity and relevance of the data it creates, collects and maintains, but especially because such data should be, by definition, public, since the information results from governmental activity and as such should be available as open data. 
Also, the data collected by private companies about citizens activities can give us a better understanding of cities metabolism. In fact, private companies increasingly acquire more importance and relevance in this context since they are rapidly becoming the true repositories of relevant urban data.

In the case of urban intelligence, open data strategies allow aspiring cities to achieve four key objectives:

- Higher levels of transparency - Allowing the citizen to understand, examine and question the action and decisions taken by the municipality requires information. The more that open data becomes public, the more we encourage participation and improve the services delivered;

- Citizens Engagement - Increasing citizens' involvement in city development and services, in decision-making processes and in participatory debate, requires citizens to understand the context in which the municipality operates. Thus, giving citizens and their communities access to operational data from the municipality and, in particular, spatially relevant data (from their "neighbourhood") helps to encourage more active and informed participation;

- Service Improvement and Efficiency Gains - Providing open data supports and accelerates the sharing of data from the municipality and other entities with expected results in improving service and gains in efficiency;

- Boost Economic Development - The release of data is now considered a "trigger" for the promotion of economic and community activity. Cities around the world already find that the massive availability of open data enables local businesses and developers to create new applications, new products and services, opening the door to the emergence of new markets.

\section{$4 \quad$ Algorithmic City Solutions for and by Citizens}

These days, creating the capacity for collecting citizens behaviour is of extreme importance, given that people are in fact the true owners of the city and to whom local governments must provide quality of life.

In effect, reality demonstrates that citizen engagement in city governance is one of the most important trends in the construction of the modern algorithmic cities. This reality is also of critical importance in the context of urban collective intelligence. Citizens' inputs are presently, as it is also demonstrated here, the most important building block to promote urban collective intelligence in the city as a platform vision.

This most relevant dimension of citizen involvement consists of adopting crowdsourcing processes to collect people's active or passive data in order to better understand a city's immediate reality and its metabolism.

\section{Active}

Active collective intelligence supports the possibility of taking advantage of citizens engagement through active participation using informal mechanisms fostered by social networks and ICTs to collect their input. Nowadays, we can find a significant number of new processes and tools that allow citizens to be active actors of the city planning and management by providing the city with their "wishes" and concerns through data supply, namely with event reporting tools and new data collection approaches. 
Regarding event reporting tools, citizens have always had the possibility to make requests or complaints, but now can make them very easily by using their phone right when they spot the problem in the public space. A significant number of digital tools make it easier and simpler for citizens to report occurrences adopting a "Fix my street" approach.

Below we can see an example of a reporting platform ("OeirasEu") displaying the events reported by the citizens through the associated smart phone application.

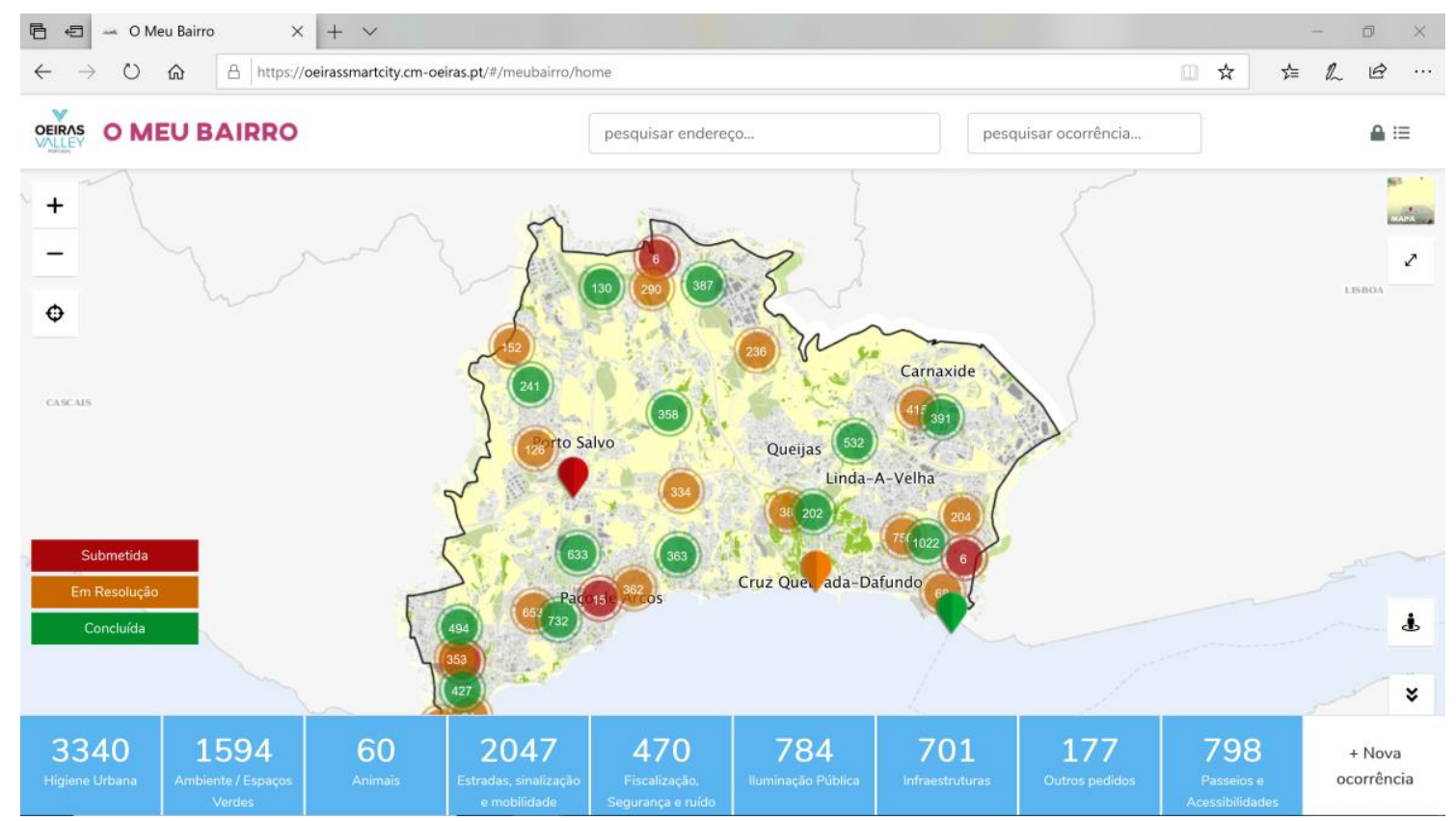

Figure 2. OeirasEu.pt Event Reporting Platform (http://oeiraseu.pt).

New data collection approaches are today possible to evaluate instantaneously citizens opinion on phenomena that will affects them. We are today witnessing emerging ways of collecting citizens' opinions to incorporate in the planning and implementation of municipal policies, such as participatory budgets or ideas contests, that can lead to a new reality of almost "direct democracy".

Figure 3 presents the Lisbon participative budget interface which is publicly available. Anyone can contribute annually with ideas and vote for the projects they wish to be implemented. 


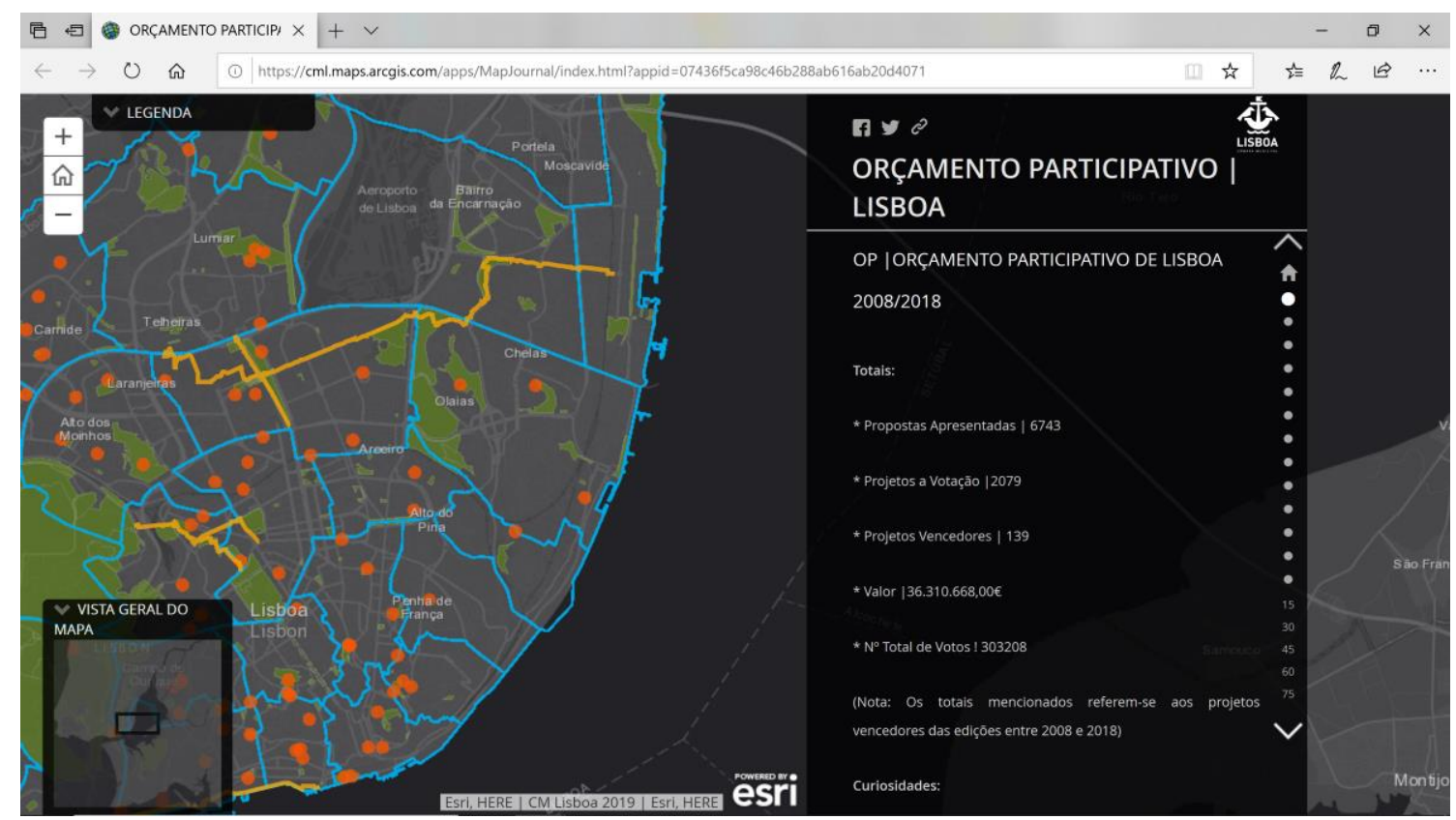

Figure 3. Lisbon Participatory Budget (https://www.lisboaparticipa.pt/).

\section{Passive}

As the fastest growing building block of urban intelligence, this modality of collective intelligence takes advantage of the sensing capacity leveraged by the data generated in a passive way by the citizens actions. Since we leave a digital footprint of almost everything we do and, respecting personal privacy through data anonymization, we can generate extremely valuable insights about the city's metabolism.

The idea of the citizens as sensors is becoming mainstream since the sheer number of people who live or work in cities with mobile phones generating location data is increasingly accepted as a valuable resource for a wide range of purposes, from traffic modelling (people and/or vehicles), urban planning, management of interventions, public health policies, creation of business opportunities, etc. Strava Global Heatmap impressively illustrates this potential by aggregating over 1 billion activities - more than 13 trillion data points - to create heatmaps of athletes' activities which can be extremely relevant for supporting city infrastructure planning like bike lanes as shown in the figure below. 


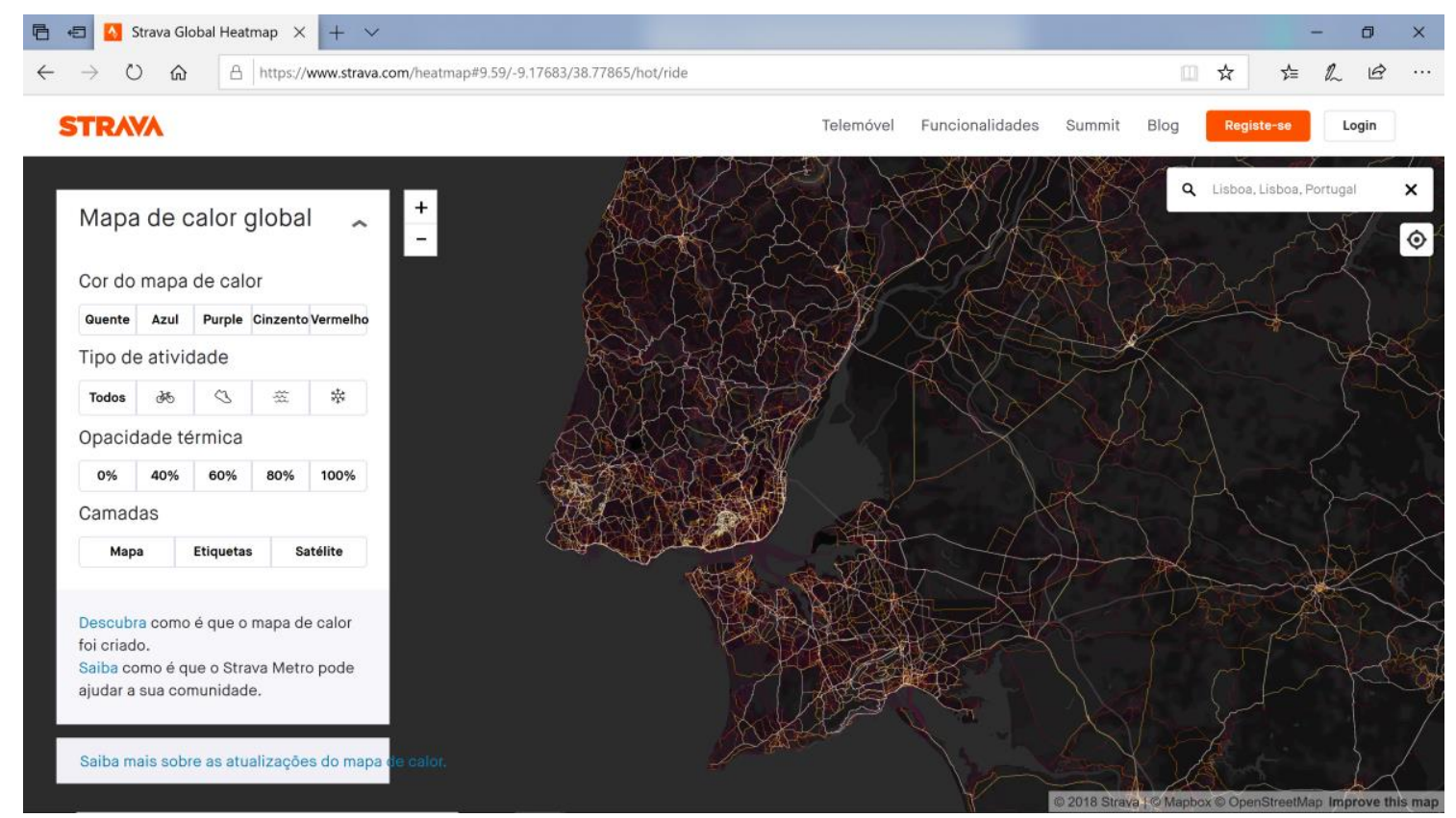

Figure 4. Strava Global Heatmap for bike activities in the Lisbon area (https://www.strava.com/ heatmap).

This concept of "the citizen as a sensor" is attracting the attention of many organizations. One of the most impressive examples is coming from the analysis of daily business transaction data, which can support not only the new insights but also to create new information, products and services. This can in fact create new data monetisation models, as demonstrated by Portuguese telco NOS. This company launched a Tourism Information Portal (http://www.nos.pt/portalturismo) based on roaming metadata supporting detailed knowledge about tourist movements over time and space, including information regarding nationality and purchasing power (the phone model is a good proxy for that purpose).

Also the behaviour of citizens made available in the social media, in particular social networks such as Facebook and Twitter, is increasingly viewed by local governments as relevant data sources and opportunities to improve city governance. Thanks to the increasing capability to analyse feelings and quantify the "Value" of the issuer of opinion, we can know immediately, and with high detail, the opinions and reactions of citizens.

The use of this approach for security purposes is generating significant debate, namely when police squads are beginning to use social media data and text mining techniques to predict crime. Currently, more than 60 American police departments use some form of "predictive policing" to guide their day-to-day operations (Ferguson, 2017).

Figure 5 presents a screenshot of "CrimeRadar", a digital platform that uses advanced machine learning to predict crime rates in different neighborhoods at different times. The first version was focused on metropolitan Rio de Janeiro and draws from over five years of crime data (roughly 14 million reported crime events) collected by the state police. By isolating patterns across incidents, locations and time, CrimeRadar is able to determine relative crime risks, tomorrow and into the next week - and also features historical crime trends going back 12 months. 


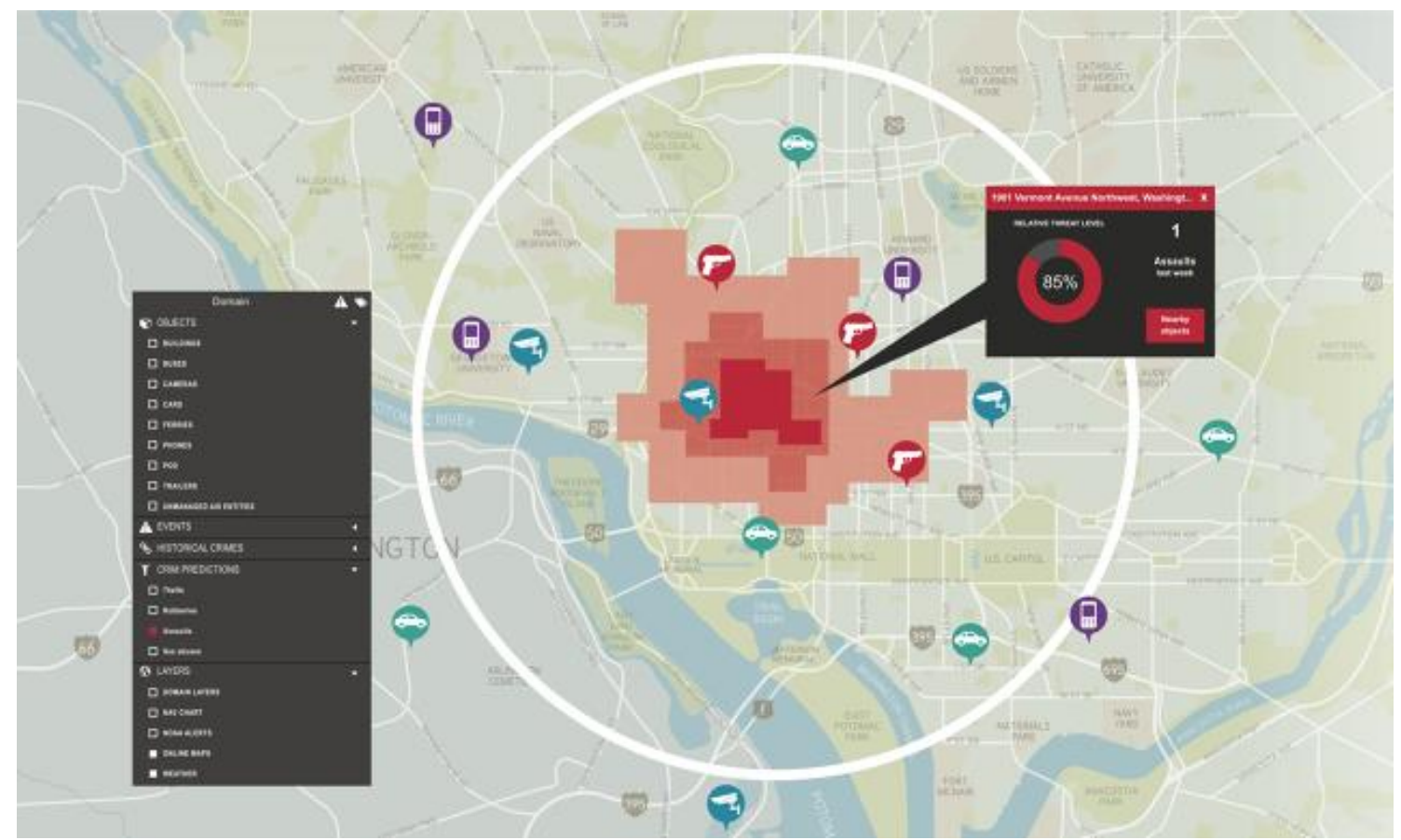

Figure 5. Hitachi Visualization Predictive Crime Analytics (https://digitalmediatecs.com/can-we-usesocial-media-to-help-predict-crimes-before-they-happen).

These are, just some examples of the fact-based and citizen-based (or collective) urban governance in the algorithmic city that we see emerging around the world in modern smart cities

\section{A Dystopic or Utopic Urban Future}

The use of urban intelligence and open data solutions can happen for implementing both dystopic or utopic policies (Fornari, 2018). However, the advance in ICTs and data science is inevitable. Therefore, it is up to governing institutions and also citizens to choose the pathway of algorithmic cities. Actually, materializing urban intelligence is a process which is increasingly facing complex legal challenges.

A recent investigation into the smartphone tracking industry, under The Privacy Project of The New York Times concluded that, every day and all over the planet, a dozens of companies, which are largely unregulated and little scrutinized, have been logging the movements of tens of millions of citizens with mobile phones and their data are being stored in gigantic data files. This study specifically focused on a selection of companies working in the location data business within the reality of the United States intended to alert citizens for the grade of exposure that they are subject to when they choose to share their locations. (Thompson \& Warzel, 2019). 


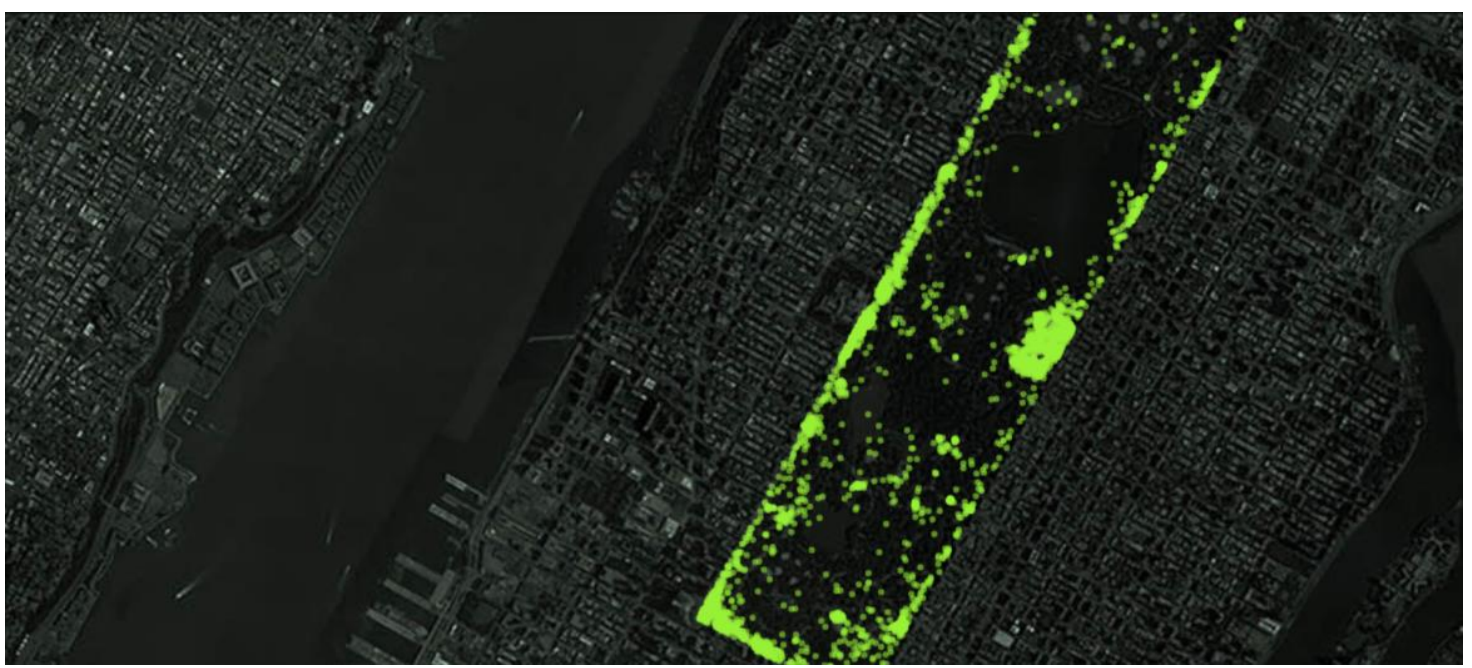

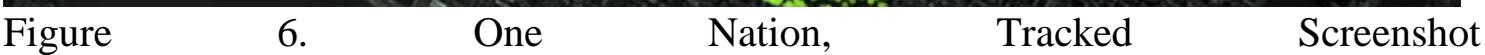
(https://www.nytimes.com/interactive/2019/12/19/opinion/location-tracking-cellphone.html)

In the reality of the European Union (EU), the General Data Protection Regulation (GDPR), approved by the Regulation (EU) 2016/679 of the European Parliament and the Council of 27 April 2016 on the protection of natural persons with regard to the processing of personal data and on the free movement of such data, intends to protect the fundamental rights and freedoms of natural persons and in particular their right to the protection of personal data, according to Article 1 GDPR. Nevertheless, the GDPR explicitly provides in its recital 26 that: "principles of data protection should (...) not apply to anonymous information, namely information which does not relate to an identified or identifiable natural person or to personal data rendered anonymous in such a manner that the data subject is not or no longer identifiable."

As a consequence, it is expressly provided in the same recital 26 that the mentioned Regulation "does not therefore concern the processing of such anonymous information, including for statistical or research purposes." European law, therefore, gives a plentiful flexibility for new perspectives of urban intelligence to coexist with the protection of the fundamental rights of citizens. Data anonymization processes must, in any case, be secured and prudently managed, respecting paramount principles such as lawfulness, fairness and transparency or even integrity and confidentiality, in accordance with the provisions of Article 5.

In fact, urban collaborative intelligence intends to enhance governance, information and well-being in the territory of cities and for all citizens, and not only for the rich (Gupte, 2020). Providing a better quality of services to citizens through smart cities' tools corresponds, naturally and consequently, to continuously improving protections of the rights of dwellers, workers and visitors who are present in that certain territory - from public security, to transportation, environment or even health (Haug, 2018:207-209).

On the other hand, urban collaborative intelligence may represent a inestimable opportunity for local governments to more easily perceive, measure, decide, and adapt to continuously changing conditions in cities, in accordance with the results that are possible to assess and measure through sensoring devices and IoT tools (Kolah, 2018). Therefore, from a good governance and citizen's well-being perspective, the benefits of urban collective intelligence will certainly play an increased and essential role at the service of the security of citizen's personal data, but also of the communities' and territories' safety against possible threats, from petty crimes to major terrorist attacks - keeping people free from danger and risk of harm. (Neto \& Cartaxo, 2019). 
Other interesting examples which can connect people with the promotion of well-being are the experiences where tech solution can crowdsource data on PET plastic by using mobile apps and therefore incentivize citizens to recycle thanks to a reward mechanism powered by blockchain. The idea of Community Inclusion Currencies (CIC), which is now being implemented in some counties of Kenya, intend to enable communities to develop a source of local credit based on productive capacity and local values, creating a monetary system better suited to eradicate poverty. These CICs are vouchers which can be used by citizens (members of the community) to buy and sell basic needs in the face of scarce national currency. CICs are then backed by the local goods and services produced by a certain community (Ridwan, Simotwo \& Visetti, 2020).

These cases demonstrate that it is up to decision, policy and lawmakers, as well as to citizens (especially to most participative ones) to contribute for the future of their cities to be whether a 1984-style dystopian reality, where citizens' individual rights are not protected, or otherwise a More's utopian urban space, in which people's well-being (or even happiness) is in the center of all city governance (Orwell, 1949; More, 1516).

\section{Conclusions and future challenges}

For the urban collective intelligence vision to materialize, in a way that can be benefic for citizens, it is essential to move from the logic of reactive urban management to a proactive logic, supported by its digital and knowledge-based transformation, broad data availability and continual updating of information. This is the reason why new solutions are needed in order to describe, predict, and prescribe: the three main verbs of future algorithmic urban governance.

An algorithmic city supported in planning, data-driven management, open data, and public participation is focused on providing quality of life to its citizens based on the empowerment of ICTs and advanced techniques of real-time data processing and analysis, in order to efficiently and sustainably operate the various subsystems that support life in cities. Urban collective intelligence in the algorithmic city can generate more efficiency and, therefore, contribute directly to the creation of more sustainable and resilient cities and to a better quality of life in urban environments, more focused on utopian than dystopian approaches.

The construction of urban collective intelligence in the algorithmic city is based on the digital transformation, on the building clocks of urban intelligence, and on open-data policies. However, this can only succeed in a smart city model which acts as a platform focused on the generation of knowledge, making data widely available and the permanent updating of information, working in a collaborative network involving government and local administration, companies, academia and, most importantly, citizens.

It is essential to emphasize that the essential principles for an algorithmic city must always be based on promoting increased transparency in governance, generating synergies with stakeholders (public administration, companies, academia and citizens), working on better quality of services on the part of the administration and service providers with greater participation of citizens in governance and in the day-to-day life of the city.

Digital transformation, which is leading to the concept of the "city as a platform," is a game-changer. The challenge that cities are facing these days is the construction of this new smart, analytical, algorithmic city, primarily focused on protecting well-being for their citizens.

At this point, ethics are paramount for an algorithmic future. An example was the recent concern demonstrated by the Vatican about the uncontrolled spread of artificial 
intelligence (AI) technologies. For this reason, forces were joined with tech corporations (Microsoft and IBM) to promote the ethical development of AI, call for regulation of intrusive technologies such as facial recognition, and use AI "as a tool for the good of humanity and the planet." This call pledges for "algor-ethics" based on the principles of (i) transparency; (ii) inclusion; (iii) responsibility; (iv) impartiality; (v) reliability; and (vi) security and privacy (Pontifical Academy for Life, 2020). This is an evidence that the world is moving at an unprecedent pace, institutions need to adapt, and the algorithmic pathway can be extremely positive and constructive for the Humankind. Nonetheless, societies must find ways of regulating it and adapt to innovation, while focused on what is better for people's well-being and even for the planet, such as in climate change issues. In fact, at the end of Book II of his Utopia (or A little, true book, not less beneficial than enjoyable, about how things should be in the new island Utopia), Thomas More concluded that "in the Utopian commonwealth there are very many features that in our societies [he] would wish rather than expect to see" (More, 1516) The utopic city may not be possible. However, what is still possible is to make use of the solutions that are made available by the algorithmic city to improve governance and the lives of its citizens.

\section{References}

Brauneis, R., \& Goodman, E. P. (2018) Algorithmic transparency for the smart city. Yale JL \& Tech., 20, 103

Caragliu, A., Del Bo, C., \& Nijkamp, P. (2009) Smart cities in Europe. In: Series Research Memoranda, 0048. VU University Amsterdam, Faculty of Economics, Business Administration and Econometrics. http://degree.ubvu.vu.n1/repec/vua/wpaper/pdf/20090048.pdf. Accessed 27 Feb 2020

Cerf, Vinton G. (2018) “Traceability”. Communications of the ACM 61(8): 7

European Parliament (2014) Mapping Smart Cities in the EU: Study, Directorate-General for Internal Policies, Policy Department A, PE 507.480

Ferguson, Andrew (2017) The Rise of Big Data Policing: Surveillance, Race, and the Future of Law Enforcement. New York: New York Press

Fornari F. (2018) City of Future. In: Karwowski W., Ahram T. (eds) Intelligent Human Systems Integration. IHSI 2018. Advances in Intelligent Systems and Computing, vol 722. Springer

Foth, M., Mitchell P., Estrada-Grajales C. (2020) Today's Internet for Tomorrow's Cities: On Algorithmic Culture and Urban Imaginaries. In: Hunsinger J., Allen M., Klastrup L. (eds) Second International Handbook of Internet Research. Springer

General Data Protection Regulation (GDPR), approved by the Regulation (EU) 2016/679 of the European Parliament and of the Council of 27 April 2016 https://eurlex.europa.eu/eli/reg/2016/679/oj. Accessed 27 Feb 2020

Gupte, J. (2020) Cities are not only for the rich. Developing future cities for all: The necessary learnings for inclusive, future infrastructures. In: UN-Habitat. Future Cities, New Economy, and Shared City Prosperity Driven by Technological Innovations. $\quad$ Nairobi: UN-Habitat: 62-69. https://unhabitat.org/sites/default/files/2020/02/future_cities_new_economy_and shared_city_prosperity_driven_by_technological_innovations_discussion_papers. pdf. Accessed 02 Mar 2020

Harrison, C., \& Abbott Donnelly, I. (2011) A Theory of Smart Cities. In: Proceedings of the 55th Annual Meeting of the ISSS. 
http://journals.isss.org/index.php/proceedings55th/ article/viewfile/1703/572.

Accessed 27 Feb 2020

Haug, C.J. (2018) "Turning the Tables - The New European General Data Protection Regulation". The New England Journal of Medicine 19: 207-209

Khatoun, R., \& Zeadally, S. (2016) "Smart Cities: Concepts, Architectures, Research Opportunities". Communications of the ACM 59(8): 46-57

Kolah, Ardi (2018) The GDPR Handbook: A Guide to Implementing the EU General Data Protection Regulation. UK: Kogan Page

Komninos, N., Panori, A., \& Kakderi, C. (2019) Smart cities beyond algorithmic logic: digital platforms, user engagement and data science. In Smart Cities in the Postalgorithmic Era. Edward Elgar Publishing

Massachusetts Institute of Technology (2013) Smart Cities Group, Cambridge, MA http://smartcities.media.mit.edu/frameset.html. Accessed 27 Feb 2020

Meijer, A., \& Bolívar, M.P.R. (2016) Governing the smart city: a review of the literature on smart urban governance. International Review of Administrative Science. Vol. 82(2): $392-408$

More, T. (1516) Utopia, ed. by George M. Logan \& Robert M. Adams (2002). Cambridge: Cambridge University Press

Navarro, J. L. A., Ruiz, V. R. L., \& Peña, D. N. (2017) The effect of ICT use and capability on knowledge-based cities. Cities, 60, 272-280.

Neto, M.N. (2018) Urban Intelligence. In 2018 Proceedings. 43. https://aisel.aisnet.org/capsi2018/43. Accessed 08 Mar 2020

Neto, M.C., \& Cartaxo, T.M. (2019) Smart and collective urban intelligence. In T. Rodrigues \& A. Inácio. Security at a Crossroad: New Tools for New Challenges. New York: Nova Science Publishers: 83-94

Neto, M.C., Rego, J.S., Cartaxo, T.M. (2017). As Cidades Inteligentes são feitas por todos: Relatório Final. Lisboa: ANMP

OECD (2015) Governing the City. Paris: OECD Publishing https://www.oecd.org/regional/regional-policy/Governing-the-City-Policy-

Highlights\%20.pdf. Accessed 27 Feb 2020

Ojo, A., Curry, E., Zeleti, F.A. (2015) A tale of open data innovations in five smart cities. In Proceedings of the 48th Hawaii International Conference on System Sciences, 2326-2335

Oomen, B., Davis, M.F., \& Grigolo, M. (eds) (2016) Global Urban Justice: The Rise of Human Rights Cities. Cambridge: Cambridge University Press

Open Knowledge International (2017) https://okfn.org/. Accessed 27 Feb 2020

Open Knowledge Foundation (2018) Open Data Handbook. http://opendatahandbook.org/. Accessed 27 Feb 2020

Orwell, G. (1949) Nineteen Eighty-Four: A Novel. London: Secker \& Warburg

Pontifical Academy for Life. (2020) Rome Call for AI Ethics. http://www.academyforlife.va/content/dam/pav/documenti\%20pdf/2020/CALL\% 2028\%20febbraio/AI\%20Rome\%20Call\%20x\%20firma_DEF_DEF_pdf. Accessed 09 Mar 2020

Ridwan, S., Simotwo, H., Visetti, P. (2020) Can we monetize and cryptify our garbage? The case of mobile technology and community inclusion cryptocurrencies for PET recycling. In: UN-Habitat. Future Cities, New Economy, and Shared City Prosperity Driven by Technological Innovations. Nairobi: UN-Habitat: 70-79.

Schaffers, H., Komninos, N., Pallot, M., Trousse, B., Nilsson, M., Oliveira, A. (2011) Smart Cities and the Future Internet: Towards Cooperation Frameworks for Open Innovation. In Domingue, J. et al (eds.) The Future Internet. FIA 2011. Lecture 
Notes in Computer Science, Vol. 6656. Berlin and Heidelberg: Springer-Verlag: 432

Thompson, S.A. \& Warzel, C. (2019) Twelve Million Phones, One Dataset, Zero Privacy. The New York Times. https://www.nytimes.com/interactive/2019/12/19/opinion/location-tracking-cellphone.html. Accessed 27 Feb 2020

Townsend, A. M. (2013). Smart Cities: Big Data, Civic Hackers, and the Quest for a New Utopia

Tyagi, S., Joshi, M., Ansari, N., \& Singh, V. K. (2019) Impact of IoT to Accomplish a Vision of Digital Transformation of Cities. Handbook of IoT and Big Data, 309.

UNEP (2017) United Nations Environment Programme. Accessed September 1, 2017. http://www.unep.org/. Accessed 27 Feb 2020

Williams, S. (2015) More Than Data: Working With Big Data For Civics. In: I/S: A Journal of Law and Policy. Vol. 11: 1-21.

United Nations (2018) Revision of World Urbanization Prospects. https://www.un.org/development/desa/en/news/population/2018-revision-ofworld-urbanization-prospects.html. Accessed 27 Feb 2020 